\title{
Insertion of central venous catheters in children undergoing bone marrow transplantation: is there a platelet level for a safe procedure?
}

\author{
Ahmed Elgendy ${ }^{1 *}$ (D) Ahmed M. Ismail ${ }^{2}$, Eslam Elhawary ${ }^{3}$, Ahmed Badran ${ }^{2}$ and Mohammed Ramadan El-Shanshory ${ }^{3}$
}

\begin{abstract}
Background: Bone marrow transplantation (BMT) is a therapeutic procedure for the management of several hematological diseases and malignancies in pediatric population. Central venous catheters (CVCs) play a pivotal role during the process of BMT. The aim of this study was to compare the complications of CVCs placements in children undergoing BMT with platelet levels above and below 50,000/ $\mu \mathrm{L}$ and also to detect if there is a platelet count for a safe insertion. This prospective study included all children who had placements of tunneled CVCs during BMT at our hospital between March 2017 and March 2020. Procedures were divided into two groups accordingly to preoperative platelet counts (above and below 50,000/ $\mathrm{LL}$ ). Data were compared between both groups regarding postoperative complications including bleeding or catheter-related blood stream infections (CRBSIs).

Results: Forty-six CVC insertions were performed in 40 patients. There were 20 procedures below 50,000/ $\mu \mathrm{L}$ (median 27,500; range 5000-42,000) inserted with perioperative platelet transfusions, and their postoperative levels were median 59,500/ $\mu \mathrm{L}$, range 18,000-88,000. Allogeneic BMT was adopted in 39 patients (97.5\%). Beta thalassemia major was the commonest indication (21/40, 52.5\%), followed by acute lymphocytic leukemia in six patients (15\%). There were nine postoperative complications (bleeding $n=2$ and CRBSIs $n=7$ ) encountered in all placements. Four of them occurred in insertions below 50,000/ $\mu \mathrm{L}$ (two bleeding complications that managed conservatively, and two CRBSIs). Post-procedural morbidities regarding bleeding or CRBSIs did not differ significantly between both groups ( $p$ value $=0.099$ and 0.695 , respectively).
\end{abstract}

Conclusions: Postponement of CVC insertions in thrombocytopenic children due to the fear of potential complications seems unwarranted, as it has no significant impact on the morbidity. Placements of such catheters can be safe under cover of perioperative platelet transfusions irrespective of the preoperative platelet count.

Keywords: Central venous catheters, Children, Thrombocytopenia, Bone marrow transplantation

\footnotetext{
* Correspondence: ahmed.elgendy@med.tanta.edu.eg

The initial result of this study has been presented as an Oral Presentation by the Corresponding Author at the 20th European Pediatric Surgical

Association Congress (EUPSA 2019), Belgrade, Serbia.

'Surgical Oncology Unit, Faculty of Medicine, Tanta University, 35 Ali Beek

Elkbeer Street, Tanta 31515, Egypt

Full list of author information is available at the end of the article
}

\section{Springer Open}

(c) The Author(s). 2020 Open Access This article is licensed under a Creative Commons Attribution 4.0 International License, which permits use, sharing, adaptation, distribution and reproduction in any medium or format, as long as you give appropriate credit to the original author(s) and the source, provide a link to the Creative Commons licence, and indicate if changes were made. The images or other third party material in this article are included in the article's Creative Commons licence, unless indicated otherwise in a credit line to the material. If material is not included in the article's Creative Commons licence and your intended use is not permitted by statutory regulation or exceeds the permitted use, you will need to obtain permission directly from the copyright holder. To view a copy of this licence, visit http://creativecommons.org/licenses/by/4.0/. 


\section{Background}

Bone marrow transplantation (BMT) is currently considered as a practiced and a well-established modality for the treatment of several hematological diseases and malignancies in children [1]. Central venous catheters (CVCs) have a crucial role in pediatric patients who are undergoing such therapeutic procedure. Their insertions could be effectively used in the infusion of chemotherapeutic drugs, stem cells, blood products, electrolyte supplements, antibiotics, and frequent venous samplings [2, 3].

Considerable numbers of children prior to the process of BMT have severe thrombocytopenia which has been correlated with a high risk of occurrence of morbidities during the placement of CVCs [4]. Some investigators have declared that insertion of these devices could be safely performed in thrombocytopenic patients with a platelet level of $50,000 / \mu \mathrm{L}$ or more without additional perioperative platelet transfusion, in the absence of other coagulation problems [5-7]. On the other hand, some surgeons are usually hesitant regarding CVC insertions in patients with preoperative platelet count less than 50 , $000 / \mu \mathrm{L}$ due to the fear of occurrence of intra- and postoperative complications. Consequently, there is sometimes a postponement of catheter placements which are essential devices due to the aforementioned purposes [8].

The purpose of this study was to compare the complications of CVC placements in children and adolescents undergoing BMT with platelet levels above and below $50,000 / \mu \mathrm{L}$ and also to detect if there is a platelet count for a safe insertion.

\section{Methods}

This is a prospective study that included all children who had placements of CVCs by the dedicated surgical team during the process of BMT at our hospital between March 2017 and March 2020. This study was approved by the institutional review board of pediatric hematology/oncology and BMT unit at our university. A written informative consent was signed by all parents or guardians for the surgical procedure, anesthesia, and data use.

All the included patients had CVC insertions 12 days before the commencement of BMT as per the adopted protocol within our hospital. All procedures were performed in the theater room under general anesthesia and complete aseptic conditions. The internal jugular vein was the preferred site considered for CVC placements in all patients. We always depend on tunneled double-lumen silicone catheters, Hickman or Broviac catheters (Medcomp, Harleysville, PA, USA) accordingly to the availability of sizes. All CVCs were inserted by the guidance of intraoperative ultrasound to avoid arterial puncture, using catheters' sizes ranged from 6 to10 Fr.
Intraoperative empirical antibiotic (cephalosporin or clindamycin, if there is allergy to cephalosporin) was administered to all patients. Venous return through the catheter was checked at the end of the surgery, and the line was flushed with heparin to prevent immediate postoperative thrombosis. Plain chest $\mathrm{x}$-rays were conducted after insertions to detect potential occurrence of pneumothorax or hemothorax and to confirm the catheter tip position and the success of the placement. Postoperative careful care of the device was managed by well-trained nurses to avoid thrombosis, infections, and catheter dysfunction.

All procedures were performed by the same standardized operative technique regardless of the preoperative platelet count. The insertions in children within the recommended level of safety $(50,000 / \mu \mathrm{L}$ or more) were performed without any platelet transfusion cover. During the procedures in patients who had platelet levels below this threshold, perioperative platelet transfusions were given $2 \mathrm{~h}$ before the scheduled placement, and bulky dressing was used after finishing the procedure to compress the surgical site. Postoperatively, complete blood pictures and all coagulation profiles were sampled for further evaluation.

Bleeding complications related to the surgical procedure including puncture-site hemorrhage or hematomas or hemothorax were classified into minor bleeding which does not need any additional surgical intervention and major bleeding which requires surgery to arrest the hemorrhage. Minor bleeding is classified as either grade 1 , i.e., oozing is stopped by slight compression, or grade 2 , i.e., oozing needs prolonged manual compression to be arrested. Major bleeding is classified into grade 3 and grade 4 that require elective and urgent interventions, respectively [4]. Catheter-related blood stream infections (CRBSIs) were considered when a clinical picture of systemic sepsis was occurred in the absence of a related cause, meanwhile associated with positive and identical bacteria obtained in blood cultures from both a CVC and a peripheral vein [9]. The pathogen count isolated from the CVC should be three times more than that identified from a peripheral venous sampling for a confirmed diagnosis [10, 11]. In the condition of a suspected CRBSI, intravenous baseline antibiotics (gram positive and gram negative) were commenced till the result of the blood culture, in addition to antimicrobial lock therapy that consists of locking catheter with an antibiotic solution while it is not in use. The removal of CVCs was indicated at the end of receiving medications, or in cases with persistent CRBSIs despite administration of the specific antibiotic or in catheter mechanical obstruction unresponsive to the flush with heparinized saline for restoring its patency. 
Data were collected from the patients' records and analyzed regarding their baseline criteria, diagnosis, preand postoperative platelet levels, other coagulation parameters, perioperative platelet transfusions, types and sizes of CVCs inserted, cause of removal, and complications encountered. The procedures were divided into two groups according to preoperative platelet counts of patients: the first group (group A) included all placements within the safety platelets level $(50,000 / \mu \mathrm{L}$ or more), while the second group (group B) contained the insertions below the same level.

Results between both groups were compared using chi-square test in addition to the usual descriptive analysis. The quantitative variables were expressed as mean \pm standard deviation [SD]. Statistical significance was accepted when the $p$ value was equal to or less than 0.05 . Statistical data analysis was performed using SPSS [Statistical Package for Social Sciences, Version 21.0].

\section{Results}

Forty patients were included for analysis, and a total of $46 \mathrm{CVCs}$ were inserted during the series period. There were 31 males (77.5\%) and 9 females (22.5\%). Mean age at time of the surgical procedure was $5.49 \pm 3.59$ years (range 2-15 years). Beta thalassemia major was the most common indication for BMT among the included children $(21 / 40,52.5 \%)$, followed by acute lymphocytic leukemia in six patients (15\%). Allogeneic BMT was adopted in 39 patients (97.5\%), whereas only one child with non-Hodgkin's lymphoma underwent an autologous transplantation.

Preoperative platelet counts for all patients ranged from 5,000 to $505,000 / \mu \mathrm{L}$ with a median of $206,000 / \mu \mathrm{L}$. Out of all children, 26 (65\%) had initial platelet counts above the safety threshold of $50,000 / \mu \mathrm{L}$, while the other 14 patients $(35 \%)$ were presented with platelet levels below the same threshold at the time of surgery. All patients underwent CVC insertions, by the same technique, during the preparation for BMT as mentioned previously in the "Methods" section. During the process of BMT, six patients had inevitable device removal; therefore, additional CVCs were placed in such patients who had platelet levels below the safety threshold during the second insertions. Second placements were performed after few days of removal of the catheter as it was the source of sepsis, and also after appropriate course of antibiotics. Consequently, groups A and B included 26 and 20 CVCs placements, respectively. The patients' clinical characteristics in both groups were listed in Table 1.

Median preoperative platelet level in group A was 232, $000 / \mu \mathrm{L}$ (range 60,000-505,000). The placements in group B had a median preoperative platelet count of 27 , $500 / \mu \mathrm{L}$ (range 5000-42,000); of them, there were 8 placements in counts less than $20,000 / \mu \mathrm{L}$ and the
Table 1 The patients' clinical characteristics in both groups

\begin{tabular}{|c|c|c|}
\hline Parameter & $\begin{array}{l}\text { Group A } \\
N(\%)\end{array}$ & $\begin{array}{l}\text { Group B } \\
N(\%)\end{array}$ \\
\hline Number of patients & $26(65 \%)$ & $14(35 \%)$ \\
\hline Number of CVCs insertions & $26(56.5 \%)$ & $20(43.5 \%)$ \\
\hline Rt. IJV & $26(100 \%)$ & $14(70 \%)$ \\
\hline Lt. IJV & - & $6(30 \%)$ \\
\hline \multicolumn{3}{|l|}{ Indication for BMT } \\
\hline Hematological diseases & $26(100 \%)$ & $3(21.4 \%)$ \\
\hline Beta Thalassemia major & 21 & - \\
\hline Acquired aplastic anemia & 2 & 2 \\
\hline Sickle-Thalassemia & 2 & - \\
\hline Mucopolysaccharaidosis & 1 & - \\
\hline Fanconi anemia & - & 1 \\
\hline Malignancies & - & $11(78.6 \%)$ \\
\hline ALL & - & 6 \\
\hline AML & - & 3 \\
\hline Non-Hodgkin's lymphoma & - & 2 \\
\hline Perioperative platelet transfusions & - & $20(100 \%)$ \\
\hline
\end{tabular}

remaining 12 were inserted in levels ranged between 25, 000 and $42,000 / \mu \mathrm{L}$. Postoperative platelet counts in group B showed an obvious improvement after preprocedural platelet transfusions; however, 8 out of the 20 procedures still had postoperative platelet levels below $50,000 / \mu \mathrm{L}$. Other coagulation parameters were within the normal values and did not demonstrate any significant difference between the groups. The comparison between both groups regarding platelet levels and coagulation parameters is shown in Table 2. There were no complications occurred due to platelet transfusions

Table 2 The comparison between both groups regarding platelet levels and coagulation parameters

\begin{tabular}{lll}
\hline Parameter & Group A & Group B \\
\hline Preoperative & & \\
PT (mean); seconds & 12.5 & 13 \\
aPTT (mean); seconds & 32 & 35.4 \\
INR; mean & 1.0 & 1.1 \\
$\quad$ Platelet count; per microliter & & \\
$\quad$ Range & $60,000-505,000$ & $5000-42,000$ \\
$\quad$ Median & 232,000 & 27,500 \\
Postoperative & & \\
$\quad$ Platelet count; per microliter & & $18,000-88,000$ \\
$\quad$ Range & $50,000-430,000$ & 59,500 \\
$\quad$ Median & 220,000 &
\end{tabular}

PT prothrombin time, aPTT activated partial thromboplastin time, INR international normalized ratio 
among the insertions in group B, and also, there were no plasma or coagulation factor transfusions in such group.

Forty CVCs were inserted into the right internal jugular vein, and only 6 were placed in the left side. Regarding the type of $\mathrm{CVCs}$ used, Hickman catheters were inserted in 30 placements $(65.2 \%)$ of all performed procedures, and in the other 16, Broviac catheters (34.8\%) were placed. Sixteen placements were of size $9 \mathrm{Fr}$, followed by 12 insertions of size $6 \mathrm{Fr}$, and CVC sizes of 7 and $10 \mathrm{Fr}$ were used in the remaining 10 and 8 procedures, respectively.

A total of nine complications were encountered among all insertions; they included 7 CRBSIs and 2 minor bleeding complications. There were no significant statistical difference between both groups regarding bleeding morbidities as only 2 out of the 20 placements in group B developed minor bleeding complications, while there were no bleeding complications in group A $(p$ value $=0.099$; hazard ratio $2.444,95 \%$ CI $0.714-$ 3.487). One patient had a hematoma after the procedure and the other had a puncture site hemorrhage, and both were managed conservatively without any surgical intervention. There were no major bleeding complications happened in group B.

Seven CRBSIs were occurred after the first placements at a median time of 21 days post-insertion, with an overall incidence of $17.5 \%$ (7/40). The CRBSIs did not achieve a significant difference, as 2 out of 14 patients below the safety level had CRBSIs versus 5 out of 26 patients above the same threshold ( $p$ value $=0.695$; hazard ratio $1.429,95 \%$ CI $0.239-8.528$ ]. All the encountered CRBSIs were happened with Hickman catheters, and during their course, 14 blood cultures were conducted from both CVC and a peripheral vein. Blood cultures have confirmed that the source of sepsis was the inserted catheter, and they were managed as aforementioned. Regarding the causative organisms in the CRBSIs, there were four, two, and one Klebsiella pneumoniae, Staphylococcus aureus, and Staphylococcus epidermidis, respectively. Three devices (one of them was inserted below the safety platelet threshold) were salvaged and passed with uncomplicated CRBSIs, while the other 4 catheters were removed due to resistant infections (Klebsiella $n=1$, Staphylococcus epidermidis $n=1$, and Staphylococcus aureus $n=2$ ). Moreover, two catheters were removed due to persistent mechanical complications; thus, six patients needed second placements. None of the included patients required a third insertion. There was neither recurrence of CRBSIs nor mortality due to infectious complications.

\section{Discussion}

Undoubtedly, CVCs are fundamental tools in the procedure of BMT. They provide the patients with a durable access for irritant parenteral drugs in addition to reduce repeated and painful cannulations [12]. The selection of the device should be based on the indication of placement and the planned duration of use. In our institution, we adopt tunneled external lines which are visible and easy to access with multiple lumens and also no needle stick is required. Despite they are associated with an increased rate of infection when compared to totally implantable ports, their removal could be performed without general anesthesia [13].

CVCs are frequently implemented in patients with hemostatic dysfunction [14]. This study discusses the correlation between platelet levels and potential complications during CVC insertion in children. Several previous reports documented the impact of thrombocytopenia on bleeding-related morbidities in adults $[7,15,16]$, while only few studies were conducted among the pediatric population $[4,17,18]$. Josephson et al. reported through an analysis of a clinical trial that bleeding risk is higher and dangerous in children, especially those during BMT, rather than in adults [19]. However, bleeding morbidities in our study were of minor grade (grade $1=$ one episode, grade $2=$ one episode) that were treated only by observation and manual compression, without any blood component transfusion. One patient who developed local hematoma had severe aplastic anemia with preoperative platelet level of 10, $000 / \mu \mathrm{L}$, and the other with acute lymphocytic leukemia that had postoperative puncture site oozing (preoperative count of $31,000 / \mu \mathrm{L}$ ), and after stopping the bleeding, both devices continued in use. Similarly, such event was reported by others in children with malignancies or chronic diseases $[4,17]$. The overall incidence of bleeding complications in our series (4.3\%) was in a reasonable range when compared to previous pediatric studies that reported $3,2.5$, and $1.1 \%$, respectively $[4,8,17]$. We believe that the slight difference in percentages among studies could be attributed to numbers of the included patients.

The present study demonstrated that preoperative platelet level has no significant correlation with the risk of bleeding-related morbidities after placements of $\mathrm{CVCs}$, and perioperative platelet transfusion can surely reduce such complication. Similar result was also declared by some investigators $[4,17,18]$. On the contrary, Zeidler et al. and Mumtaz et al. reported that associated thrombocytopenia was a risk factor for the occurrence of local hematoma or minor bleeding after device insertion $[7,15]$.

Bloodstream infection is a prevalent complication after catheter placement in immunocompromised children. The tracing of the source of infection is usually a challenge. CRBSIs occur very early due to imperfect sterile technique during port insertion and considered as a 
surgical complication, or later on due to associated risk factors or poor device care [20]. The frequency of CRBSIs among pediatric oncology patients is ranging from 9.8 to $22 \%$ [21, 22]. In our study, such rate was $15.2 \%$, and similarly, near results were declared by others in immunocompromised patients with incidence of 17.6, 18.9 , and $10.7 \%$, respectively $[8,17,23]$. We did not observe any significant role of thrombocytopenia in relation to the occurrence of CRBSIs. Similarly, our result was in line with previous studies that aimed to assess such factor in children with leukemia [8, 17]. In contradiction, Bamba et al. reported that low preoperative platelet count was a significant risk factor for device infection [20]. Another cohort study revealed that percentage of CRBSIs was equal between patients with platelet levels above and below $50,000 / \mu \mathrm{L}$ after radiological implementation of CVCs [24].

In this study, gram-negative bacteria were the most common organism isolated in episodes of CRBSIs (57\%). The predominance of such negative bacilli was also reported previously by other studies involving patients undergoing BMT or with malignancies; Zanwar et al. and Chee et al. showed that 83 and $68 \%$ of their cases with CRBSIs were due to gram-negative organisms [23, 25]. Out of all episodes of CRBSIs occurred among our patients, $43 \%$ of catheters were salvaged by systemic antibiotics in addition to antimicrobial lock therapy that used as an adjunct modality. Such strategy was also conducted by a recent study, demonstrating a salvage rate of $83 \%$ [23], and it was effective towards gram-negative organisms in that study as well as our finding. Eventually, the decision of device removal is critical, and it mainly relies on the clinical course of the infection and the response of the child. The removal should balance between adding another surgical procedure with potential morbidity, meanwhile avoiding deterioration of the patient due to uncontrolled sepsis.

The majority of surgeons adopt a cutoff of 50,000/ $\mu \mathrm{L}$ for pre-procedural platelet transfusion during port insertion in both children and adults $[4,20]$. A review of practice conducted on adult patients recommended that $20,000 / \mu \mathrm{L}$ should be a safe level, and CVCs could be implemented without perioperative platelet transfusions or potential risks [7]. They also declared that platelet transfusion should be only reserved to patients with levels below 20,000/ $\mu \mathrm{L}$ [7]. Evidencebased guidelines are still lacking in the pediatric literature towards this recommendation. Based on the results of this series, we believe that no platelet level is required for safe insertion in children, and empirical platelet transfusions can secure the procedure especially with experienced hands and ultrasound guidance to achieve a one-trial vein cannulation.

\section{Conclusions}

Postponement of CVC insertions in thrombocytopenic children due to the fear of potential morbidities seems unwarranted as thrombocytopenia has no significant impact on both, bleeding complications or CRBSIs. Placements of such catheters can be safe in any patient under cover of perioperative platelet transfusions irrespective of the preoperative platelet count, especially with experienced hands under ultrasound guidance.

\begin{abstract}
Abbreviations
CVCs: Central venous catheters; BMT: Bone marrow transplantation; CRBSIs: Catheter-related blood stream infections; SD: Standard deviation; SPSS: Statistical Package for Social Sciences
\end{abstract}

\section{Acknowledgments \\ The authors gratefully thank Mr. Ahmed Samir Ryad for the technical assistance in the manuscript.}

\section{Authors' contributions}

Study design: AE; Data collection: EE; Data analysis: AE; Manuscript writing: AE; Manuscript critical review: AE; The authors read and approved the final manuscript.

\section{Funding}

This research did not receive any specific grant from funding agencies in the public, commercial, or not-for-profit sectors.

\section{Availability of data and materials}

The datasets used and/or analyzed during the current study are available from the corresponding author on a reasonable request.

\section{Ethics approval and consent to participate}

This study was approved by the institutional review board and research ethical committee of pediatric hematology/oncology and BMT unit at the Faculty of Medicine, Tanta University, with an approval number of 14726/01/ 17. A written consent was obtained from all study participants.

\section{Consent for publication}

Written informed consents were signed by all parents for surgery and data use in scientific purpose only at the time of management at our center. This consent was clearly stated in the manuscript in the "Methods" section. All private data of patients such as name, address, and phone number or even identity photos will not appear in the research. The consents are in the patients' medical records.

\section{Competing interests}

The authors declare that they have no competing interests.

\section{Author details \\ ${ }^{1}$ Surgical Oncology Unit, Faculty of Medicine, Tanta University, 35 Ali Beek Elkbeer Street, Tanta 31515, Egypt. ${ }^{2}$ Vascular Surgery Department, Faculty of Medicine, Tanta University, Tanta, Egypt. ${ }^{3}$ Pediatric Hematology/Oncology and Bone Marrow Transplantation Unit, Pediatrics Department, Faculty of Medicine, Tanta University, Tanta, Egypt.}

Received: 27 July 2020 Accepted: 20 October 2020

Published online: 30 November 2020

\section{References}

1. Armitage JO. Bone marrow transplantation. N Engl J Med. 1994;330:827-38.

2. Milford K, von Delft D, Majola N, Cox S. Long-term vascular access in differently resourced settings: a review of indications, devices, techniques, and complications. Pediatr Surg Int. 2020;36(5):551-62.

3. Masumoto K, Uesugi T, Nagata K, Takada N, Taguchi S, Ogita K, et al. Safe techniques for inserting the Hickman catheter in pediatric patients. Pediatr Hematol Oncol. 2006;23(7):531-40. 
4. Olivieri C, Crocoli A, De Pasquale MD, Inserra A. Central venous catheter placement in children with thrombocytopenia. Minerva Pediatr. 2016;68(6) 398-403.

5. Schiffer CA, Anderson KC, Bennett CL, Bernstein S, Elting LS, Goldsmith M, et al. Platelet transfusion for patients with cancer: clinical practice guidelines of the American Society of Clinical Oncology. J Clin Oncol. 2001;19:1519-38.

6. British Committee for Standards in Haematology BTTF. Guidelines for the use of platelet transfusions. Br J Haematol. 2003;122:10-23.

7. Zeidler K, Arn K, Senn O, Schanz U, Stussi G. Optimal preprocedural platelet transfusion threshold for central venous catheter insertions in patients with thrombocytopenia. Transfusion. 2011;51(11):2269-76.

8. Loh $\mathrm{AH}$, Chui $\mathrm{CH}$. Port-A-Cath insertions in acute leukemia: does thrombocytopenia affect morbidity? J Pediatr Surg. 2007;42(7):1180-4.

9. Allen RC, Holdsworth MT, Johnson CA, Chavez CM, Heideman RL, Overturf $\mathrm{G}$, et al. Risk determinants for catheter-associated blood stream infections in children and young adults with cancer. Pediatr Blood Cancer. 2008:51:53-8.

10. Lissauer ME, Leekha S, Preas MA, Thom KA, Johnson SB. Risk factors for central line-associated bloodstream infections in the era of best practice. J Trauma Acute Care Surg. 2012;72(5):1174-80.

11. Carter JH, Langley JM, Kuhle S, Kirkland S. Risk factors for central venous catheter-associated bloodstream infection in pediatric patients: a cohort study. Infect Control Hosp Epidemiol. 2016;37(8):939-45.

12. Alshafei A, Tareen F, Maphango N, White D, O'Connor B, Sriparan T. Open tunneled central line insertion in children-external or internal jugular vein? J Pediatr Surg. 2018;53(11):2318-21.

13. Cesaro S, Corro R, Pelosin A, Gamba P, Zadra N, Fusaro F, et al. A prospective survey on incidence and outcome of Broviac/Hickman catheterrelated complications in pediatric patients affected by hematological and oncological diseases. Ann Hematol. 2004;83:183-8.

14. van de Weerdt EK, Biemond BJ, Baake B, Vermin B, Binnekade JM, van Lienden KP, et al. Central venous catheter placement in coagulopathic patients: risk factors and incidence of bleeding complications. Transfusion. 2017;57(10):2512-25

15. Mumtaz H, Williams V, Hauer-Jensen M, Rowe M, Henry-Tillman RS, Heaton $\mathrm{K}$, et al. Central venous catheter placement in patients with disorders of hemostasis. Am J Surg. 2000;180:503-5.

16. Doefler ME, Kaufman B, Goldenberg AS. Central venous catheter placement in patients with disorders of hemostasis. Chest. 1996;110:185-8.

17. Loh $\mathrm{AH}$, Chui $\mathrm{CH}$. Port-A-Cath insertions in acute leukaemia and childhood malignancies. Asian J Surg. 2007;30(3):193-9.

18. Weil BR, Andreoli SP, Billmire DF. Bleeding risk for surgical dialysis procedures in children with hemolytic uremic syndrome. Pediatr Nephrol. 2010;25:1693-8.

19. Josephson CD, Granger S, Assmann SF, Castillejo MI, Strauss RG, Slichter SJ, et al. Bleeding risks are higher in children versus adults given prophylactic platelet transfusions for treatment-induced hypoproliferative thrombocytopenia. Blood. 2012;120:748-60.

20. Bamba R, Lorenz JM, Lale AJ, Funaki BS, Zangan SM. Clinical predictors of port infections within the first 30 days of placement. J Vasc Interv Radiol. 2014;25(3):419-23.

21. Fernandez-Pineda I, Ortega-Laureano L, Wu H, Wu J, Sandoval JA, Rao BN, et al. Guidewire catheter exchange in pediatric oncology: indications, postoperative complications, and outcomes. Pediatr Blood Cancer. 2016; 63(6):1081-5.

22. Gonzalez G, Davidoff AM, Howard SC, Pui CH, Rao BN, Shenep JL, et al. Safety of central venous catheter placement at diagnosis of acute lymphoblastic leukemia in children. Pediatr Blood Cancer. 2012;58(4):498-502.

23. Zanwar S, Jain P, Gokarn A, Devadas SK, Punatar S, Khurana S, et al. Antibiotic lock therapy for salvage of tunneled central venous catheters with catheter colonization and catheter-related bloodstream infection. Transpl Infect Dis. 2019;21(1):e13017. https://doi.org/10.1111/tid.13017.

24. Ray CE Jr, Shenoy SS. Patients with thrombocytopenia: outcome of radiologic placement of central venous access devices. Radiology. 1997; 204(1):97-9.

25. Chee L, Brown M, Sasadeusz J, MacGregor L, Grigg AP. Gram-negative organisms predominate in Hickman line-related infections in nonneutropenic patients with hematological malignancies. J Inf Secur. 2008; 56(4):227-33.

\section{Publisher's Note}

Springer Nature remains neutral with regard to jurisdictional claims in published maps and institutional affiliations.

\section{Submit your manuscript to a SpringerOpen ${ }^{\circ}$ journal and benefit from:}

- Convenient online submission

- Rigorous peer review

- Open access: articles freely available online

- High visibility within the field

- Retaining the copyright to your article

Submit your next manuscript at $\boldsymbol{\nabla}$ springeropen.com 